\title{
IoT based Garbage Monitoring System
}

\author{
Deepti Patole \\ Information Technology \\ Department \\ KJ Somaiya College of \\ Engineering \\ Mumbai, India \\ India
}

\author{
Darshan Panchal \\ Information Technology \\ Department \\ KJ Somaiya College of \\ Engineering \\ Mumbai, India
}

\author{
Krishna Sampat \\ Information Technology \\ Department \\ KJ Somaiya College of \\ Engineering \\ Mumbai, India
}

\author{
Saurabh Nagare \\ Information Technology \\ Department \\ KJ Somaiya College of \\ Engineering \\ Mumbai, India
}

\begin{abstract}
One of the major problems that world is facing today is waste management. Most of the times it is seen that the waste is been spilled over the bins and lying nearby. This leads to spreading of some deadly diseases in the surrounding environment. Also, people find it difficult to walk beside with it. All these problems are due to lack of coordination and communication among the garbage team members. Also the study has revealed that the waste management can be far more efficient if the garbage is segregated at source and then disposed in dumping grounds separately. Thus, there is a big need to have a proper waste management.
\end{abstract}

Considering the above issues, this paper proposes a system, that will try to reduce these problems to a greater extent. This system initially segregates the waste and then monitors the garbage level in bins using IoT. This data related to bin level is sent to a server over internet, where the system processes the real time data and raises alerts to manage the collection of Waste. The proposed system also takes care of long time goal of identifying the pattern of waste generation at various localities. This data collected by the system can be used to further plan the effective measures to reduce the waste mismanagement and to maintain cleaner environment.

\section{General Terms}

Internet of Things, Clean Environment

\section{Keywords}

Garbage monitoring, Garbage segregation. Smart Garbage bins

\section{INTRODUCTION}

As it is known that India is the second most populated country after China. Due to increasing population, the waste generation is also uplifting. This leads to haphazardly dumping of garbage which in turn causes ill effects on the environment and on physical conditions of people. India is still a developing country so it is important for it to work more in the direction of "Smart Country". To collect the waste from societies, schools, hotels, industries, restaurants and from a lot more areas proper communication with the garbage collector needs to be maintained. If there are any delays among the stakeholders there can be an overflow of garbage. The current scenario is collecting the garbage as a whole and then dumping it all together. To alleviate such situation, in this paper a system is proposed which not only segregates the waste as dry and wet but also indicates the amount of waste in the trash bins.

\section{LITERATURE SURVEY}

Municipality takes numerous measures to keep up the neatness of the city. One of which is setting up dustbins in customary separation for the comfort of general society to dispose of things. Cleaning this junk is an essential capacity of the district which is straightforwardly identified with medical problems. A model is outlined for a "Smart Dustbin" which shows specifically that the dustbin is filled to aspecific level by the waste and cleaning or purging them involves prompt concern.

This avoids lumping of rubbish in the roadside dustbin which winds up giving foul smell and disease to people. The circuit to control up the mechanical gadgets is additionally gathered to get the expected output. The paper [1] Smart Garbage Management in Smart Cities using IoT proposed a method as follows. The level of trash in the dustbins is observed with the assistance for ultrasonic sensors framework and interfaced to the approved control room through GSM framework.

An alternate system to waste management is acquainted in [2] likewise. A dustbin is interfaced with an microcontroller-based framework Hosting IR remote frameworks alongside central framework indicating that current status about garbage, with respect to portable web program for HTML page. Henceforth the status will be updated once on the HTML page. Thereby to decrease human assets and deliberations alongside with the improvement of an advanced mobile city.

A Geological data framework transportation model for robust waste accumulation that elaborates arrangements to waste storage, gathering and transfer has been suggested in [3] for the city of Asansol situated in India. An improved directing and planning waste gathering model is suggested to the Eastern Finland, emphasizing the use of a guided variable neighborhood threshold meta-heuristic. The main motive is to create an ideal calendar to trucks looking into characterized gathering routes.

This paper [4] proposes an advanced mobile caution framework for trash cleaning by eventually providing for a caution indicator to the metropolitan web server for immediate cleaning of dustbin with proper confirmation of level of trash filling. This procedure is helped by ultrasonic sensor, which is connected with Arduino UNO to weigh the level of waste loaded in the dustbin then sends the caution of the level to metropolitan web server once waste is filled. Then after cleaning the dustbin, the driver confirms the assignment about discharging the waste with the help of RFID tag. RFID is a registering innovation organization that is utilized for confirmation methodology. Also in addition, it likewise enhances the trash caution framework by giving programmed ID number of waste filled in the dustbin and sends the status about clean-up to the server affirming that effort is finished.

This paper [5] endeavors to display a review about DSS in the region of strong waste economy for particular reference to their evolution and requisitions done in India. There shows up a positive requirement for improvement of client inviting EDSS for robust waste economy to Indian regulative social set up. An applied outline system for one such recommended 
system, named 'EDSSMSWI' was examined.

\section{EXISTING SYSTEM}

The existing system collects garbage once a day. It can also happen that sometimes waste spills out of the bins.

Its unhygienic for the people too and leads to bad odor around the surrounding and leads to spreading some deadly diseases. To tackle such situation, a system is proposed named as "IoT based Garbage Monitoring System".

\section{PROPOSED SYSTEM}

The system initially segregates the waste into dry and wet type, then detects the level of garbage in bins and monitors it by sending real-time data to server. Thus, the project involves three phases: Segregation, Level Detection and Monitoring data.

\subsection{Segregation Phase}

This is the first step that takes place when the system is turned ON. Depending upon the type of waste entered by user (i.e. dry or wet), the system segregates this waste into dry and wet bins accordingly. This is done with the help of pipe which is driven by motor. The motor rotates the pipe in the direction of wet or dry bin depending upon the type of waste detected.

\subsection{Level Detection Phase}

As the garbage gets filled in the bins, the ultrasonic sensor which is mounted at the top of bins, detects the current level of garbage in bins.

\subsection{Monitoring Data Phase}

This data is then sent to server. The server then updates the data of the web page and helps in real-time monitoring of the system. Also, an SMS is send to the registered mobile number of the garbage collector person regarding this data. The garbage administrator can then plan for collection of garbage from only those bins which are filled to a certain level.

\section{SYSTEM ARCHITECTURE}

\subsection{Smart Garbage Bins}

Smart Garbage Bins are provided with an ultrasonic sensor to detect the garbage level of the bins. The proposed system has two bins i.e. Dry and Wet to collect respective type of waste.

\subsection{Garbage Segregation}

This system segregates the dry waste and wet waste separately. For that, a moisture and humidity sensors are used. If the moisture sensor detects the waste as wet, then the pipe will rotate in the direction of the wet bin and vice-versa.

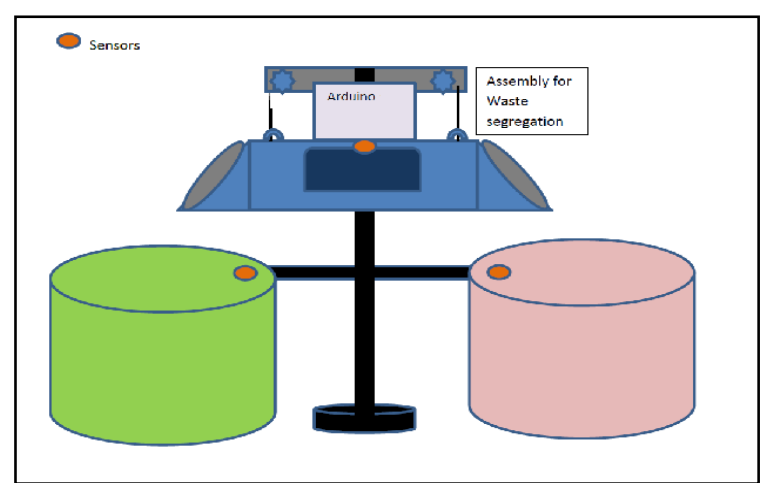

Figure 1: Smart Garbage Bin

\subsection{Arduino}

Arduino Nano has been used in this project which has all the sensors mounted on it. It is programmed in C language. It is the main unit of this project.

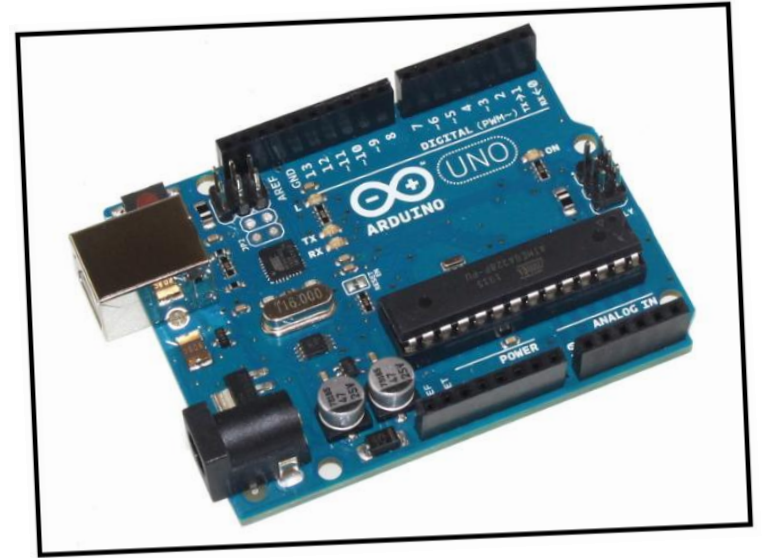

Figure 2: Arduino Nano

\subsection{GSM Modem}

The module collects the bins data and updates it to the server and also send the notification via SMS to the collector.

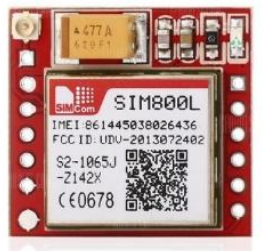

Figure 3: Gsm Modem

\subsection{Web Server}

The Cloud server is used in the project. It is programmed in ASP.NET. It connects the web application with the Arduino Board.

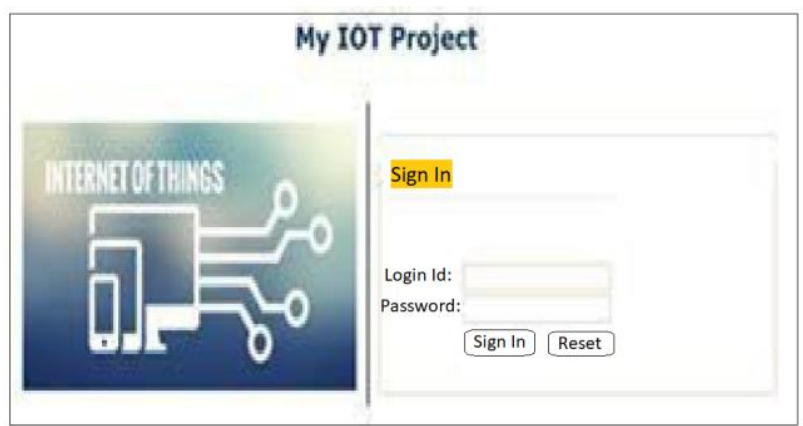

Figure 4: Web server login page

\subsection{Collector}

The collector on receiving the notification takes the vehicle to the location from where it has received the request. 


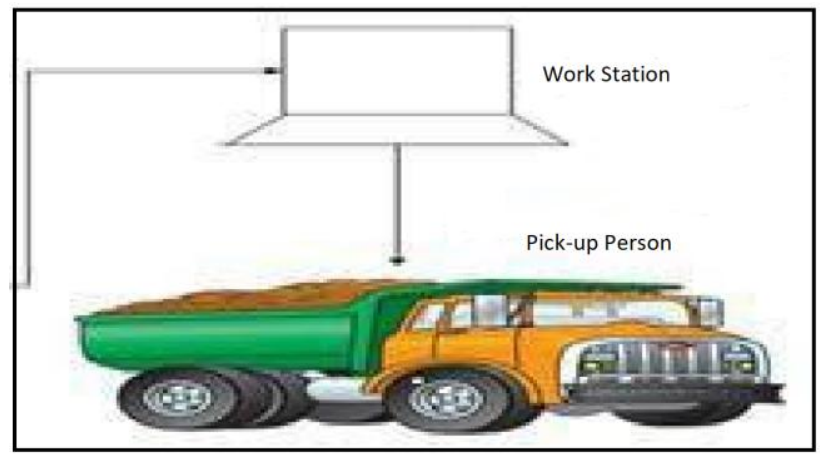

Figure 5: Collector

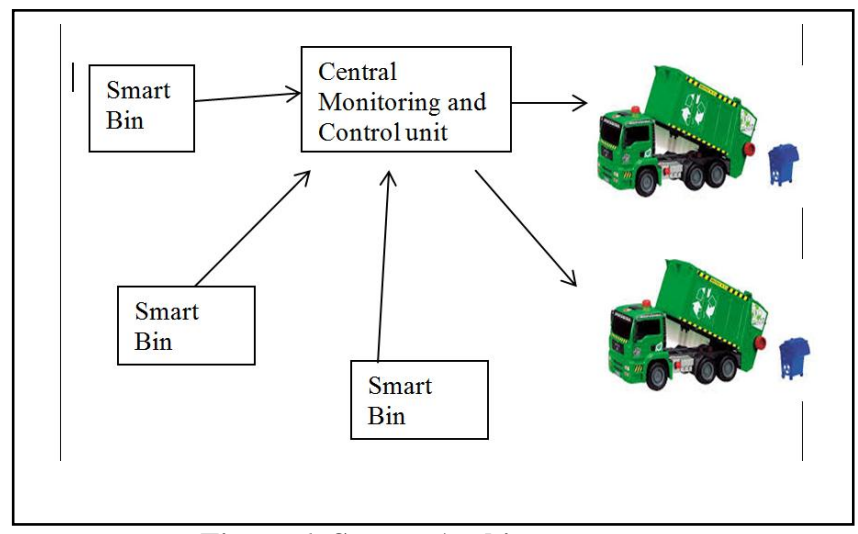

Figure 6: System Architecture

\section{RESULTS}

Table 1. System analysis

\begin{tabular}{|l|l|l|}
\hline $\begin{array}{c}\text { Sr. } \\
\text { No. }\end{array}$ & Parameters considered & \multicolumn{1}{|c|}{ Value } \\
\hline 1 & Time taken for segregation & 10 seconds \\
\hline 2 & $\begin{array}{l}\text { Approximate Assembly } \\
\text { Size }\end{array}$ & $\begin{array}{l}75 \mathrm{~cm} \text { x 25cm x } \\
75 \mathrm{~cm}\end{array}$ \\
\hline 3 & Power requirement & $12 \mathrm{~V}, 2 \mathrm{~A}$ DC \\
\hline 4 & Transportation efficiency & $\begin{array}{l}\text { Garbage truck trips } \\
\text { become demand } \\
\text { based, } \\
\text { optimized. }\end{array}$ \\
\hline 5 & Spill Over Probability & 0.1 \\
\hline 6 & $\begin{array}{l}\text { Reduction } \\
\text { in } \\
\text { mass } \\
\text { of garbage. }\end{array}$ & $\begin{array}{l}\text { Recyclable-10\% } \\
\text { Non-Recyclable- } \\
90 \%\end{array}$ \\
\hline
\end{tabular}

\section{DISCUSSION}

By reviewing various paper, it has been observed that management of garbage is a very crucial thing and numerous types of technology are used for it. In these papers the level of garbage using ultrasonic and IR sensor is detected. In this, IoT is responsible for measuring the waste level in the dry and wet bins and later send this data (through Internet) to a server for storage and processing.

\section{CONCLUSION}

To conclude from the researches carried out on waste management worldwide, the garbage needs to be segregated and then disposed appropriately. This can help in reducing huge pyramids forming at the garbage dumping grounds.

This model segregates the litter effectively from its source itself. This will help to cut down the tedious and monotonous process of the waste segregation.

This system integrates for garbage monitoring and collection in a way which enables optimum use of resources. The system proposes a real time optimum solution for a tiresome problem of junk management. The system improves the garbage management by reducing the possibility of spill over of rubbish in cities.

The system also provides a broader overview of scrap generation pattern of the city which further can be utilized for better planning of waste management by centrally providing the real time scenario of any locality where the system is employed.

\section{FUTURE WORK}

In future, the data can be enhanced, that is stored on the server helps to compute the optimized collection routes for the collector. The scope for future work is the implementation of same system with less complexity at affordable costs and more security to the sensors so its life is increased.

\section{ACKNOWLEDGEMENTS}

We sincerely express our gratitude towards the Department of Information Technology, K.J. Somaiya College of Engineering.

\section{REFERENCES}

[1].Vikrant Bhor, Pankaj Morajkar, Maheshwar Gurav, Dishant Pandya, "Smart Garbage Management System", March 2015.

[2]. S.S. Navghane, M.S. Killedar, Dr.V.M. Rohokale," IoT Based Garbage and Waste Collection Bin", May 2016

[3]. Ghose, M.K., Dikshit, A.K., Sharma, S.K. "A GIS based transportation model for solid waste disposal A case study on Asansol municipality. Journal of Waste Management", April 2015.

[4]. Dr.N. Sathish Kumar, B. Vijayalakshmi, R. Jenifer Prarthana, A. Shankar, "IoT Based Smart Garbage alert system using Arduino UNO”, IEEE, May 2016.

[5]. A. Ohri and P. K. Singh, Development of decision support system for municipal solid waste management in India: A review, International journal of environmental science, June 2016

[6]. Kanchan Mahajan, Waste Bin Monitoring System Using Integrated Technologies, International Journal of Innovative Research in Science, July 2014.

[7]. Sara Ojeda Benitz, Gabriela Lozona-Olvera, Raul Adalberto Morelos, Carolina Armijo de Vaga, Mathematical Modelling to predict residential solid waste management, Waste Management, Volume 28, 2008, Pages S7-S13, ISSN 0956-053X.

[8]. Akash k t, Dinesh choudhari S Y, Sandeep C U, Prof. Rashmi PM "IoT BASED GARBAGE MONITORINGSYSTEM”, April 2017

[9]. Dr. K. Alice Mary, Perreddy Monica, A. 
Apsurrunisa, Chathala Sreekanth, G. Pavan Kumar Professor "IoT BASED GARBAGE MONITORING SYSTEM", April 2017

[10]. Prof. Dr. Sandip M. Chaaware, Shreeram Dighe, Akshay Joshi, Namrata Bajare, Rohini Korke "Smart Garbage Monitoring System using Internet of Things (IoT)", January 2017

[11] Kasliwal Manasi H and Suryawanshi Smithkumar B 2016 A Novel approach to Garbage Management Using Internet of Things for smart cities International Journal of Current Trends in Engineering \& Research 2 348-53

[12] Medvedev A, Fedchenkov P, Zaslavsky A, Anagnostopoulos T and Khoruzhnikov S 2015 Waste management as an IoT-enabled service in smart cities In Conference on Smart Spaces Springer International Publishing 104-15

[13] Monika K A, Rao N, Prapulla S B and Shobha G 2016 Smart Dustbin-An Efficient Garbage Monitoring System International Journal of Engineering Science and Computing 6 7113-16* 